\title{
Association between energy-dense food consumption at 2 years of age and diet quality at 4 years of age
}

\author{
Sofia Vilela ${ }^{1}$, Andreia Oliveira ${ }^{1,2,3}$, Elisabete Ramos ${ }^{1,2,3}$, Pedro Moreira ${ }^{1,4}$, Henrique Barros ${ }^{1,2,3}$ and \\ Carla Lopes ${ }^{1,2,3 *}$ \\ ${ }^{1}$ Institute of Public Health, University of Porto, Porto, Portugal \\ ${ }^{2}$ Department of Clinical Epidemiology, Predictive Medicine and Public Health, University of Porto Medical School, \\ Rua Doutor Plácido da Costa, 4200-450 Porto, Portugal \\ ${ }^{3}$ Cardiovascular Research and Development Unit, University of Porto Medical School, Porto, Portugal \\ ${ }^{4}$ Faculty of Nutrition and Food Sciences, University of Porto, Porto, Portugal \\ (Submitted 16 May 2013 - Final revision received 7 October 2013 - Accepted 8 October 2013 - First published online 14 November 2013)
}

\section{Abstract}

The present study aimed to evaluate the association between the consumption of energy-dense foods at 2 years of age and the consumption of foods and diet quality at 4 years of age. The sample included 705 children evaluated at 2 and 4 years of age, as part of the population-based birth cohort Generation XXI (Porto, Portugal). Data on sociodemographic and lifestyle factors of both children and mothers were collected by face-to-face interviews. The weight and height of children were measured by trained professionals. Based on FFQ, four energy-dense food groups were defined: soft drinks; sweets; cakes; salty snacks. A healthy eating index was developed using the WHO dietary recommendations for children (2006) aged 4 years. The associations were evaluated through Poisson regression models. After adjustment for maternal age and education, child's carer, child's siblings and child's BMI, higher consumption of energydense foods at 2 years of age was found to be associated with higher consumption of the same foods 2 years later. An inverse association was found between the intake ( $\geq$ median) of soft drinks (incidence rate ratio (IRR) $=0.74,95 \%$ CI $0.58,0.95$ ), salty snacks (IRR $=0.80$, $95 \%$ CI $0.65,1.00)$ and sweets (IRR $=0.73,95 \%$ CI $0.58,0.91)$ at 2 years of age and the consumption of fruit and vegetables at 4 years of age ( $\geq 5$ times/d). Weekly and daily consumption of energy-dense foods at 2 years of age was associated with a lower healthy eating score at 4 years of age (IRR $=0.75,95 \%$ CI $0.58,0.96$; IRR $=0.56,95 \%$ CI $0.41,0.77$, respectively). The consumption of energydense foods at young ages is negatively associated with the diet quality of children a few years later.

Key words: Energy-dense foods: Diet quality: Preschool children

Energy-dense foods are foods generally high in energy but with a low nutrient content ${ }^{(1)}$. The consequences of the consumption of this type of foods on health have been studied through different components. Some studies have focused more on foods high in sugar such as sugar-sweetened beverages ${ }^{(2-4)}$, candies $^{(5,6)}$, confectionery $^{(7)}$ and chocolates ${ }^{(8-10)}$. Others have been more interested in foods with a high fat content such as snacks ${ }^{(11)}$ and fast foods ${ }^{(12,13)}$. The per capita daily energy contribution from sugar-sweetened beverages in US children aged 2-5 years increased from $448 \mathrm{~kJ}(107 \mathrm{kcal})$ in $1988-94$ to $519 \mathrm{~kJ}$ (124 kcal) in 1999-2004 ${ }^{(14)}$. Snacking has also increased in US children $^{(15)}$. Compared with children of other age groups, children aged 2-6 years consumed the highest amount of daily snacks and showed the largest increase in intake from 1977 to 2006 (approximately an increase of 1.41 events) ${ }^{(15)}$. In Europe, the daily consumption of soft drinks ranges from $10 \%$ (Finland) to $40 \%$ (Bulgaria) in school-aged children. Almost one-third of children eat sweets or chocolates on a daily basis ${ }^{(16)}$. In a national survey carried out in 1997/1998 among British children aged 4-6 years, $80 \%$ of children were found to consume foods such as savoury snacks, potato chips and confectionery at least once a week $^{(17)}$. In Portugal, among school-aged children, the daily consumption of soft drinks was observed in $21 \%$ of girls and $30 \%$ of boys and sweets were consumed daily by $20 \%$ overall $^{(16,18)}$.

Previous studies have highlighted the adverse health effects of the consumption of energy-dense food in both children and adults, particularly on body weight ${ }^{(12,19-22)}$. The consumption of energy-dense foods also seems to have an adverse effect on the overall diet quality in children. A study ${ }^{(13)}$ conducted among children and adolescents in a national household survey in the USA has found that children who ate fast

Abbreviation: IRR, incidence rate ratio.

* Corresponding author: C. Lopes, fax +351 225513 653, email carlal@med.up.pt 
foods, compared with those who did not, had a significantly higher intake of total energy, total fat, saturated fat, added sugars and sugar-sweetened beverages and a significantly lower intake of dietary fibre, milk, fruit and starchy vegetables. Other studies ${ }^{(23,24)}$ have found an association between increasing intake of added sugars and decreasing intake of some nutrients, such as protein, fat, vitamins $\mathrm{A}$ and $\mathrm{E}$ and folate. Moreover, higher consumption of sugar-sweetened beverages has been shown to be negatively associated with diet quality in children and adolescents ${ }^{(25,26)}$. Lower diet quality scores have been reported to be associated with increased disease risk and all-cause mortality rates in adulthood ${ }^{(27)}$. Most of these studies had used a cross-sectional approach to study the association between the consumption of presumed lesshealthy foods and the diet quality of children ${ }^{(13,23,24,26,28,29)}$. The use of a longitudinal analysis among young preschool children has been less explored ${ }^{(25,30,31)}$.

The aim of the present study was to evaluate the prospective association between the consumption of less-healthy foods at 2 years of age and the consumption of foods at 4 years of age. The relationship between the consumption of energy-dense foods at 2 years of age and the consumption of similar food groups and diet quality at 4 years of age was explored.

\section{Methods}

\section{Subjects}

The present study is based on the prospective population-based birth cohort Generation XXI, which has been described elsewhere ${ }^{(32-34)}$. Generation XXI recruited newborns and their mothers during 2005-6 at five level III maternity units of Porto. Of the invited mothers, $91.4 \%$ agreed to participate. A total of 8647 children and 8495 mothers were enrolled at baseline. At 2 years of age, a subsample of 855 children was re-evaluated (April-August 2007 and January 2008). In 2009/2011, all the children (at 4-5 years of age) and their mothers were invited to attend the first follow-up session of the entire cohort. During this evaluation period, the participants were invited to participate in an interview and a physical examination, with $86 \%$ of the children being re-evaluated at $4-5$ years of age.

Data obtained from 708 singleton children and their mothers evaluated at both 2 years of age (25 (SD 3.5) months) and 4 years of age ( 49 (SD 7.2) months) were analysed.

\section{Data collection}

Data, at both 2 and $4-5$ years of age, were collected by trained interviewers in face-to-face interviews, through structured questionnaires including information on parents' sociodemographic characteristics and children's health status and behavioural characteristics.

\section{Dietary intake}

Information on dietary intake at 2 and $4-5$ years of age was collected using a FFQ, which the main carer (usually the mother) answered in a face-to-face interview. At 2 years of age, the FFQ queried about the current frequency of consumption of seventeen food items not usually consumed on a daily basis (e.g. crisps, cakes and burgers). A total of six response options were available: 'every day'; '3-6 times per week'; '1-2 times per week'; ' $1-3$ times per month'; 'less than once a month'; 'never'. At $4-5$ years of age, the FFQ queried about the frequency of intake of thirty-five food items. For each food item, the parents or carers were asked as to how many times, on average, their children had consumed these food items during the previous 6 months. The nine frequency responses were as follows: ' 4 or more times per d'; '2-3 times per d'; ' 1 time per d'; '5-6 times per week'; '2-4 times per week'; '1 time per week'; ' $1-3$ times per month'; 'less than once a month'; 'never'. Daily frequencies of consumption were calculated using both the questionnaires (e.g. 3-6 times per week was converted into a mean of 4.5 times per week, meaning $4.5 / 7 \mathrm{~d}=0.6423$ times per $\mathrm{d}$ ).

At 2 and 4 years of age, four similar energy-dense food groups were created, including only foods comparable at both ages: soft drinks (sweetened carbonated drinks and other sweetened drinks, including diet drinks); salty snacks (crisps, pizzas and burgers); cakes (creamy cakes, not creamy cakes and sweet pastries); sweets (chocolates and candies). At both ages, the sample median consumption of energy-dense food groups was used to create dichotomic variables: consumption lower than the median $v$. consumption higher or equal to the median. At 2 years of age, in addition to the median consumption, tertiles of consumption of energy-dense foods were obtained.

At 2 and 4 years, the carers were asked to complete 2 and $3 \mathrm{~d}$ food records, respectively. Pearson's correlation coefficients were calculated for key groups comparing the responses from the FFQ and those from the food records at both ages, to assess the validation of the FFQ. A weak-tomoderate correlation was found for most of the food groups evaluated (data not shown). With the exception of sweets $(r$ 0.531), a weak correlation was found at 2 years of age.

\section{Healthy eating index}

Based on dietary recommendations for children proposed by the World Health Organization ${ }^{(35)}$, a healthy eating index was developed at 4 years of age, including only data of foods and not those on nutrient content. This index comprises seven food groups: fruit and vegetables (vegetable soup, raw and cooked vegetables and fruit); dairy foods (semi-skimmed milk, skimmed milk, cheese and yogurts); red meat and meat products (pork, beef, veal, goat, processed meats and savoury pastries); white meat and fish (rabbit, poultry, eggs and fish); soft drinks (sweetened carbonated drinks and other sweetened drinks, including diet drinks); salty snacks (crisps, pizzas and burgers); sweet snacks (cakes, sweet pastries, chocolates and candies). For each food group, quartiles of consumption were calculated, and a score ranging from 1 to 4 was assigned. For 'healthy foods' such as fruit, vegetables, white meat and fish, and dairy foods, the lowest quartile of consumption was assigned a score of 1 , intermediate quartiles were given the scores 2 and 3, and the highest 
quartile was given a score of 4 . The food groups that are not recommended for a healthy diet such as soft drinks and salty and sweet snacks were scored in the reverse direction with the highest quartile of consumption receiving the lowest score. The possible range score of the final index is $7-28$. Overall, a higher score represents a better diet at 4 years of age. The final score was stratified by the median score of 17 .

\section{Covariables}

Variables collected at the 4-5-year follow-up evaluation and used for the present analysis include the following: maternal age and education (as continuous variables); child's siblings (none, younger or older); child's current carer (family/ babysitter or kindergarten/school); child's sex. The weight and height of children were measured by a team of experienced investigators. Weight was measured in light clothing and without shoes using a digital scale and was recorded to the nearest $0.1 \mathrm{~kg}$. Height was measured as the distance from the top of the head to the bottom of the feet without shoes using a fixed stadiometer to the nearest $0.1 \mathrm{~cm}$. The BMI of children was defined as weight in $\mathrm{kg}$ divided by height in $\mathrm{m}^{2}$. This continuous variable was then categorised using specific cut-offs for sex and age specified by the $\mathrm{WHO}^{(36)}$ and re-categorised into underweight/normal (BMI $<2 \mathrm{SD})$ and overweight/obese (BMI $\geq 2 \mathrm{sD}$ ).

\section{Ethical approval}

The project Generation XXI was conducted according to the guidelines laid down in the Declaration of Helsinki, and all procedures involving human subjects were approved by the Ethical Committee of São João Hospital/University of Porto Medical School. The project was approved by the Portuguese Authority of Data Protection. Legal representatives of each participant were informed about the benefits and potential discomfort, and written informed consent was obtained for the collection of information at baseline and follow-up evaluations.

\section{Statistical analyses}

Mean values with standard deviations and frequency differences were compared using Student's $t$ test and $\chi^{2}$ test, respectively.

Associations between consumption at 2 years of age and that at 4 years of age were estimated by crude and adjusted incidence rate ratios (IRR) and respective 95\% CI, using Poisson regression. The models were adjusted for maternal age and education in years (as continuous variables), child's siblings (none, younger or older), child's current carer (family/babysitter or kindergarten/school) and child's BMI (underweight/normal or overweight/obese). The total person-time at risk was calculated, and the log of personmonths (mean $=24$ months) was included as the offset variable. A potential interaction effect of maternal education levels on the association between the consumption of energy-dense foods at 2 years of age and the healthy eating index at 4 years of age was also assessed, by including an interaction term in the final models. The analyses were conducted using the SPSS 20.0 software (SPSS Inc., 2011).

\section{Results}

In Table 1 , the characteristics of eligible participants are compared with those of the remaining cohort evaluated at baseline. In the present study, mothers were slightly more educated (11.2 (SD 4.33) v. 10.4 (SD 4.24) years, $P<0.001)$ and older (30.4 (SD 5.02) v. 29.4 (SD 5.64) years, $P<0.001$ ) than the remaining mothers evaluated at baseline. In the study sample, more children were being taken care of by family or babysitter (18.4 v. 10.7\%, P<0.001). No significant differences were found concerning child's sex and BMI and child's siblings.

Fig. 1 shows the proportion of children consuming each energy-dense food group at least once a week at 2 and 4 years of age. Most children were consuming sweets (92.0\%) and soft drinks $(63.2 \%)$ at least once a week at 4 years of age. Cakes and salty snacks were least consumed at both ages. Among those who had already been consuming these foods at least once a week at 2 years of age, the percentage of consumers at 4 years of age was $97 \cdot 4,87 \cdot 8,63 \cdot 8$ and $72 \%$ for sweets, soft drinks, cakes and salty snacks, respectively.

Table 2 summarises the crude and adjusted associations between the consumption of energy-dense foods at 2 years of age and that at 4 years of age. Overall, higher consumption at 2 years of age was positively associated with higher consumption of the same foods at 4 years of age. The strongest

Table 1. Comparison between characteristics of eligible participants and those of the remaining cohort evaluated at baseline ${ }^{\star}$

(Number of participants and percentages; mean values and standard deviations)

\begin{tabular}{|c|c|c|c|c|c|}
\hline & \multicolumn{2}{|c|}{$\begin{array}{c}\text { Sample† } \\
(n \text { 705) }\end{array}$} & \multicolumn{2}{|c|}{$\begin{array}{l}\text { Remaining } \\
\text { cohort: } \\
(n 7942)\end{array}$} & \multirow[b]{2}{*}{$P$} \\
\hline & $n$ & $\%$ & $n$ & $\%$ & \\
\hline Child's sex (boy) & 362 & $51 \cdot 3$ & 4042 & $50 \cdot 9$ & 0.822 \\
\hline \multicolumn{6}{|l|}{ Child's siblings } \\
\hline None & 320 & 45.5 & 3008 & 44.7 & \\
\hline Younger & 13 & 1.8 & 196 & 2.9 & \\
\hline Older & 370 & $52 \cdot 6$ & 3523 & $52 \cdot 4$ & 0.264 \\
\hline \multicolumn{6}{|l|}{ Child's carers§ } \\
\hline Family/babysitter & 127 & $18 \cdot 4$ & 670 & $10 \cdot 7$ & \\
\hline Kindergarten/school & 562 & 81.6 & 5611 & $89 \cdot 3$ & $<0.001$ \\
\hline \multicolumn{6}{|l|}{ Child's BMI§ $\left(\mathrm{kg} / \mathrm{m}^{2}\right)$} \\
\hline Underweight/normal & 618 & $90 \cdot 1$ & 4469 & 89.5 & \\
\hline Overweight/obese & 68 & $9 \cdot 9$ & 524 & 10.5 & 0.640 \\
\hline Maternal age (years) & \multirow{2}{*}{\multicolumn{2}{|c|}{$30 \cdot 4$}} & \multirow{2}{*}{\multicolumn{2}{|c|}{29.4}} & $<0.001$ \\
\hline Mean & & & & & \\
\hline SD & \multicolumn{2}{|c|}{$5 \cdot 02$} & \multicolumn{2}{|c|}{$5 \cdot 64$} & \\
\hline Maternal education (years) & & & & & $<0.001$ \\
\hline Mean & \multicolumn{2}{|c|}{$11 \cdot 2$} & & \\
\hline SD & \multicolumn{2}{|c|}{4.33} & \multicolumn{2}{|c|}{$4 \cdot 24$} & \\
\hline
\end{tabular}

${ }^{*}$ For each variable, the total may not add to $705 / 7942$ due to missing data † Children evaluated at 2 and 4 years of age.

$\ddagger$ Cohort evaluated at baseline.

$\S$ Characteristics evaluated in the follow-up evaluation at $4-5$ years of age ( $n 6753)$

\footnotetext{
energy-dense foods at 2 years of age and the healthy eating
} 


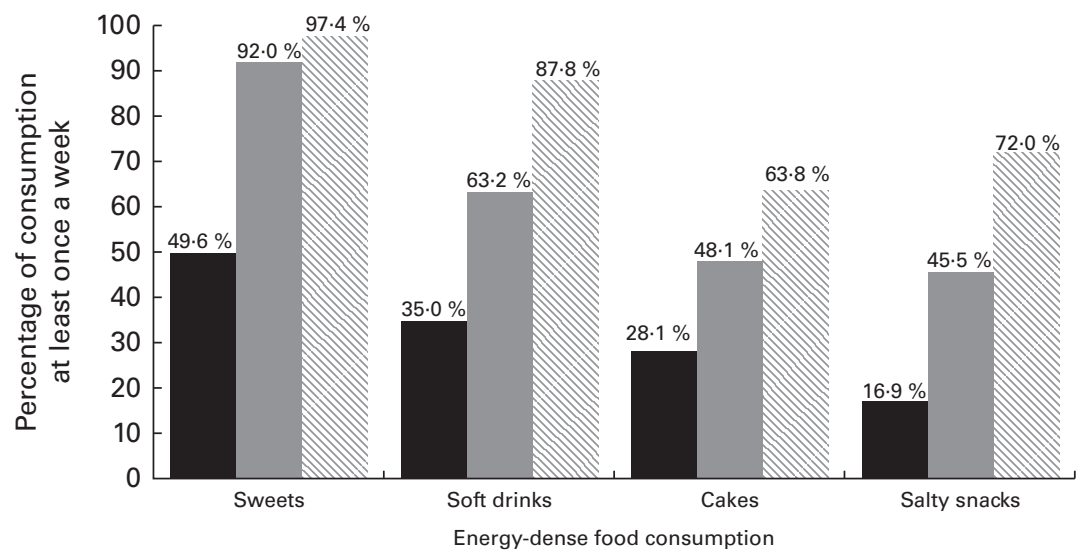

Fig. 1. Proportion of children consuming energy-dense foods at least once a week at 2 and 4 years of age. $\square, 2$ years (all sample); $\square, 4$ years (all sample); N, 4 years (among those who consumed $\geq 1 /$ week at 2 years).

effect was found for soft drinks (third $v$. first tertile: IRR $=3 \cdot 33$, $95 \%$ CI $2 \cdot 36,4 \cdot 70)$.

Table 3 presents the associations between the consumption of energy-dense foods at 2 years of age and the consumption of the remaining food groups included in the healthy eating index at 4 years of age. The final index of the study sample ranged from 7 to 25. After adjustment, a higher intake of soft drinks (IRR $=0.74,95 \%$ CI $0.58,0.95)$, salty snacks

Table 2. Associations between the consumption of energy-dense foods at 2 years of age and the consumption of similar foods at 4 years of age (Incidence rate ratios (IRR) and $95 \%$ confidence intervals)

\begin{tabular}{|c|c|c|c|c|}
\hline & \multicolumn{4}{|c|}{$\begin{array}{c}\text { Consumption at } 4 \text { years }(\geq \text { median } v . \\
<\text { median })^{\star}\end{array}$} \\
\hline & \multicolumn{2}{|c|}{ Crude } & \multicolumn{2}{|c|}{ Adjusted† } \\
\hline & IRR & $95 \% \mathrm{Cl}$ & IRR & $95 \% \mathrm{Cl}$ \\
\hline \multicolumn{5}{|c|}{ Soft drinks at 2 years $\ddagger$} \\
\hline First tertile & $1 \S$ & & $1 \S$ & \\
\hline Second tertile & 2.37 & $1 \cdot 73,3 \cdot 25$ & $2 \cdot 22$ & $1.59,3.09$ \\
\hline Third tertile & 3.64 & $2.65,4.98$ & 3.33 & $2 \cdot 36,4 \cdot 70$ \\
\hline \multicolumn{5}{|c|}{ Salty snacks at 2 yearsł } \\
\hline First tertile & $1 \S$ & & $1 \S$ & \\
\hline Second tertile & 1.55 & $1.21,1.98$ & 1.53 & $1.18,1.97$ \\
\hline Third tertile & 1.66 & $1.34,2.07$ & 1.63 & $1.30,2.04$ \\
\hline \multicolumn{5}{|l|}{ Cakes at 2 years $\ddagger$} \\
\hline First tertile & $1 \S$ & & $1 \S$ & \\
\hline Second tertile & 1.23 & $0.91,1.66$ & 1.26 & $0.93,1.71$ \\
\hline Third tertile & 1.61 & $1.24,2.08$ & 1.60 & $1 \cdot 23,2 \cdot 10$ \\
\hline \multicolumn{5}{|c|}{ Sweets at 2 years $\ddagger$} \\
\hline First tertile & $1 \S$ & & $1 \S$ & \\
\hline Second tertile & 1.45 & $1 \cdot 13,1.87$ & 1.44 & $1.11,1.88$ \\
\hline Third tertile & 1.69 & $1 \cdot 32,2 \cdot 18$ & 1.65 & $1 \cdot 27,2 \cdot 16$ \\
\hline
\end{tabular}

* Median of consumption at 4 years of age: soft drinks - 1.5 times per week; salty snacks - 0.9 times per week; cakes -1 time per week; sweets -6 times per week.

† Adjusted for maternal age and education, child's siblings, child's carer and child's BMI.

$¥$ Tertiles of consumption at 2 years of age: soft drinks - first tertile $(0$ times per week), second tertile $(>0-1.5$ times per week), and third tertile $(>1.5$ times per week); salty snacks - first tertile ( $\leq 0.1$ times per week), second tertile $(>0.1-$ 0.5 times per week), and third tertile ( $>0.5$ times per week); cakes - first tertile $(\leq 0.1$ times per week), second tertile $(>0.1-0.6$ times per week), and third tertile ( $>0.6$ times per week); sweets - first tertile ( $\leq 0.5$ times per week), second tertile ( $>0.5-2.0$ times per week), and third tertile ( $>2.0$ per week). $\S$ Reference class.
$(\mathrm{IRR}=0.80,95 \%$ CI $0.65,1 \cdot 00)$ and sweets (IRR $=0.73,95 \%$ CI $0.58,0.91)$ at 2 years of age was inversely associated with the intake of fruit and vegetables at 4 years of age. No significant associations with dairy foods, red meat and meat products, and white meat and fish were found. An increasing frequency of consumption of any energy-dense food was significantly associated with a lower intake of fruit and vegetables (weekly $v$. monthly: IRR $=0.77$, 95\% CI 0.59 , 0.99; daily $v$. monthly: $\operatorname{IRR}=0.61,95 \%$ CI $0.44,0.83$ ). A significant crude association was found between the consumption of energy-dense foods and the intake of red meat and meat products (IRR $=1.50,95 \%$ CI 1.09, 2.06); however, after adjustment, the association did not remain statistically significant.

In the multivariate analysis, higher consumption of each of the energy-dense foods, except cakes, at 2 years of age was significantly associated with a lower score in the healthy eating index at 4 years of age. Weekly and daily consumption of any energy-dense food was associated with a worse diet quality, compared with less frequent consumption $(\mathrm{IRR}=0.75,95 \%$ CI $0.58,0.96 ; \quad \mathrm{IRR}=0.56,95 \%$ CI 0.41 , $0 \cdot 77$, respectively) (Table 4 ). The potential modifying effect of maternal education was tested using an interaction term in the final model, and no significant interaction effect was observed $(P>0.05)$.

\section{Discussion}

The present study shows that the consumption of energydense foods at 2 years of age is independently associated with higher consumption of these foods later and is related to a poorer diet quality at 4 years of age.

Children consuming soft drinks more often at 2 years of age were approximately three times more likely to consume soft drinks at 4 years of age, and this was the strongest association found. This finding raises concern, as sugar-sweetened beverages have been reported to be significantly associated with childhood obesity due to both a high glycaemic index and a weak compensatory response to beverages ${ }^{(37)}$. On the other hand, salty snacks, cakes and sweets are high-energy-dense 
Table 3. Associations between the consumption of energy-dense foods at 2 years of age and the consumption of different food groups at 4 years of age (Incidence rate ratios (IRR) and $95 \%$ confidence intervals)

\begin{tabular}{|c|c|c|c|c|c|c|c|c|c|c|c|c|c|c|c|c|}
\hline & \multicolumn{16}{|c|}{ Consumption at 4 years $(\geq \text { median } v .<\text { median })^{*}$} \\
\hline & \multicolumn{4}{|c|}{ Fruit and vegetables } & \multicolumn{4}{|c|}{ Dairy foods } & \multicolumn{4}{|c|}{ Red meat and meat products } & \multicolumn{4}{|c|}{ Lean meat and fish } \\
\hline & \multicolumn{2}{|c|}{ Crude } & \multicolumn{2}{|c|}{ Adjusted $\dagger$} & \multicolumn{2}{|c|}{ Crude } & \multicolumn{2}{|c|}{ Adjusted $\dagger$} & \multicolumn{2}{|c|}{ Crude } & \multicolumn{2}{|c|}{ Adjusted $\dagger$} & \multicolumn{2}{|c|}{ Crude } & \multicolumn{2}{|c|}{ Adjusted $\dagger$} \\
\hline & IRR & $95 \% \mathrm{Cl}$ & IRR & $95 \% \mathrm{Cl}$ & IRR & $95 \% \mathrm{Cl}$ & IRR & $95 \% \mathrm{Cl}$ & IRR & $95 \% \mathrm{Cl}$ & IRR & $95 \% \mathrm{Cl}$ & IRR & $95 \% \mathrm{Cl}$ & IRR & $95 \% \mathrm{Cl}$ \\
\hline \multicolumn{17}{|l|}{ Soft drinks at 2 yearsł } \\
\hline$<$ Median & $1 \S$ & & $1 \S$ & & $1 \S$ & & $1 \S$ & & $1 \S$ & & $1 \S$ & & $1 \S$ & & $1 \S$ & \\
\hline$\geq$ Median & 0.68 & $\begin{array}{r}0.54 \\
0.85\end{array}$ & 0.74 & $\begin{array}{r}0.58 \\
0.95\end{array}$ & $1 \cdot 10$ & $\begin{array}{r}0.92 \\
1.34\end{array}$ & 1.07 & $\begin{array}{r}0.87 \\
1.30\end{array}$ & $1 \cdot 29$ & $\begin{array}{r}1.04 \\
1.60\end{array}$ & $1 \cdot 18$ & $\begin{array}{r}0.94 \\
1.49\end{array}$ & 0.92 & $\begin{array}{r}0.76 \\
1.13\end{array}$ & 1.00 & $\begin{array}{r}0.81 \\
1.25\end{array}$ \\
\hline \multicolumn{17}{|l|}{ Salty snacks at 2 yearsł } \\
\hline$<$ Median & $1 \S$ & & $1 \S$ & & $1 \S$ & & $1 \S$ & & $1 \S$ & & $1 \S$ & & $1 \S$ & & & \\
\hline$\geq$ Median & 0.77 & $\begin{array}{l}0.63 \\
0.95\end{array}$ & 0.80 & $\begin{array}{l}0.65 \\
1.00\end{array}$ & 1.03 & $\begin{array}{l}0.85 \\
1.25\end{array}$ & 1.00 & $\begin{array}{l}0 \cdot 83 \\
1.21\end{array}$ & $1 \cdot 20$ & $\begin{array}{l}0.97 \\
1.49\end{array}$ & 1.14 & $\begin{array}{l}0.91 \\
1.43\end{array}$ & 0.94 & $\begin{array}{l}0 \cdot 78 \\
1 \cdot 15\end{array}$ & 0.97 & $\begin{array}{l}0 \cdot 80 \\
1 \cdot 19\end{array}$ \\
\hline \multicolumn{17}{|l|}{ Cakes at 2 years $\ddagger$} \\
\hline$<$ Median & $1 \S$ & & $1 \S$ & & $1 \S$ & & $1 \S$ & & $1 \S$ & & $1 \S$ & & $1 \S$ & & $1 \S$ & \\
\hline$\geq$ Median & 0.84 & $\begin{array}{l}0.68 \\
1.05\end{array}$ & 0.89 & $\begin{array}{l}0 \cdot 70 \\
1 \cdot 12\end{array}$ & 1.06 & $\begin{array}{l}0 \cdot 88 \\
1.29\end{array}$ & 1.05 & $\begin{array}{l}0 \cdot 86 \\
1.28\end{array}$ & $1 \cdot 16$ & $\begin{array}{l}0.93 \\
1.44\end{array}$ & 1.08 & $\begin{array}{l}0 \cdot 86 \\
1.36\end{array}$ & 0.84 & $\begin{array}{l}0.68 \\
1.04\end{array}$ & $0 \cdot 87$ & $\begin{array}{l}0.70 \\
1.08\end{array}$ \\
\hline \multicolumn{17}{|l|}{ Sweets at 2 years $\ddagger$} \\
\hline$<$ Median & $1 \S$ & & $1 \S$ & & $1 \S$ & & $1 \S$ & & $1 \S$ & & $1 \S$ & & $1 \S$ & & $1 \S$ & \\
\hline$\geq$ Median & 0.67 & $\begin{array}{l}0.55 \\
0.83\end{array}$ & 0.73 & $\begin{array}{l}0.58 \\
0.91\end{array}$ & 1.06 & $\begin{array}{l}0 \cdot 88 \\
1 \cdot 27\end{array}$ & 1.05 & $\begin{array}{l}0 \cdot 86 \\
1 \cdot 27\end{array}$ & $1 \cdot 13$ & $\begin{array}{l}0 \cdot 90 \\
1.41\end{array}$ & $1 \cdot 14$ & $\begin{array}{l}0.91 \\
1.43\end{array}$ & 1.00 & $\begin{array}{l}0 \cdot 83 \\
1 \cdot 22\end{array}$ & 1.09 & $\begin{array}{l}0.89 \\
1.34\end{array}$ \\
\hline \multicolumn{17}{|l|}{$\begin{array}{l}\text { Energy-dense foods at } \\
2 \text { years } \|\end{array}$} \\
\hline$<1$ time per week & $1 \S$ & & $1 \S$ & & $1 \S$ & & $1 \S$ & & $1 \S$ & & $1 \S$ & & $1 \S$ & & $1 \S$ & \\
\hline Weekly & 0.73 & $\begin{array}{l}0.57 \\
0.93\end{array}$ & 0.77 & $\begin{array}{l}0.59 \\
0.99\end{array}$ & $1 \cdot 11$ & $\begin{array}{l}0 \cdot 86 \\
1.41\end{array}$ & 1.07 & $\begin{array}{l}0.82 \\
1.38\end{array}$ & $1 \cdot 17$ & $\begin{array}{l}0.86 \\
1.60\end{array}$ & 1.09 & $\begin{array}{l}0.80 \\
1.50\end{array}$ & 0.85 & $\begin{array}{l}0.66 \\
1.08\end{array}$ & 0.90 & $\begin{array}{l}0.70 \\
1 \cdot 17\end{array}$ \\
\hline Daily & 0.53 & $\begin{array}{l}0.40 \\
0.71\end{array}$ & 0.61 & $\begin{array}{l}0.44 \\
0.83\end{array}$ & $1 \cdot 13$ & $\begin{array}{l}0.87 \\
1.48\end{array}$ & 1.09 & $\begin{array}{l}0.82 \\
1.45\end{array}$ & 1.50 & $\begin{array}{l}1.09 \\
2.06\end{array}$ & 1.31 & $\begin{array}{l}0.94 \\
1.84\end{array}$ & 0.86 & $\begin{array}{l}0 \cdot 66 \\
1 \cdot 12\end{array}$ & 0.97 & $\begin{array}{l}0.72 \\
1.30\end{array}$ \\
\hline
\end{tabular}

* Median of consumption: fruit and vegetables -5 times per $d$; dairy foods -3.5 times per d; fatty meat and meat products -11.5 times per week; lean meat and fish -1.3 times per $d$. † Adjusted for maternal age and education, child's siblings, child's carer and child's BMI.

\# Median of consumption: soft drinks 0.5 times per week; salty snacks 0.2 times per week; cakes 0.5 times per week; sweets 1.0 time per week.

$\S$ Reference class.

|| Includes soft drinks, salty snacks, cakes and sweets. Sample size by categories of consumption: <1 time per week ( $n$ 147); weekly ( $n$ 339); daily $(n 214)$. 
Table 4. Associations between the consumption of energy-dense foods at 2 years of age and the healthy eating index at 4 years of age

(Incidence rate ratios (IRR) and 95\% confidence intervals)

\begin{tabular}{|c|c|c|c|c|c|c|}
\hline & \multicolumn{6}{|c|}{ Consumption at 4 years } \\
\hline & \multicolumn{6}{|c|}{ Healthy eating index $(\geq \text { median } v .<\text { median })^{\star}$} \\
\hline & \multicolumn{4}{|c|}{ Crude } & \multicolumn{2}{|c|}{ Adjusted $\dagger$} \\
\hline & Mean & SD & IRR & $95 \% \mathrm{Cl}$ & IRR & $95 \% \mathrm{Cl}$ \\
\hline \multicolumn{7}{|l|}{ Soft drinks at 2 years $\ddagger$} \\
\hline$<$ Median & $18 \cdot 1$ & 3.52 & $1 \S$ & & $1 \S$ & \\
\hline$\geq$ Median & $16 \cdot 3$ & 4.92 & 0.55 & $0.44,0.69$ & 0.64 & $0.50,0.83$ \\
\hline \multicolumn{7}{|c|}{ Salty snacks at 2 years $\ddagger$} \\
\hline$<$ Median & $18 \cdot 1$ & 3.77 & $1 \S$ & & $1 \S$ & \\
\hline$\geq$ Median & $15 \cdot 9$ & 3.36 & 0.65 & $0.53,0.80$ & 0.70 & $0.57,0.87$ \\
\hline \multicolumn{7}{|l|}{ Cakes at 2 years $\ddagger$} \\
\hline$<$ Median & $20 \cdot 3$ & 4.50 & $1 \S$ & & $1 \S$ & \\
\hline$\geq$ Median & $17 \cdot 4$ & 3.67 & 0.78 & $0.62,0.97$ & 0.84 & $0.66,1.06$ \\
\hline \multicolumn{7}{|l|}{ Sweets at 2 years $\ddagger$} \\
\hline$<$ Median & $19 \cdot 3$ & $5 \cdot 62$ & $1 \S$ & & $1 \S$ & \\
\hline$\geq$ Median & 18.1 & 3.66 & 0.62 & $0.50,0.76$ & 0.73 & $0.58,0.91$ \\
\hline \multicolumn{7}{|c|}{ Energy-dense foods at 2 years $\|$} \\
\hline$<1$ time per week & 19.4 & 3.32 & $1 \S$ & & $1 \S$ & \\
\hline Weekly & $17 \cdot 0$ & 3.46 & 0.67 & $0.53,0.85$ & 0.75 & $0.58,0.96$ \\
\hline Daily & $15 \cdot 2$ & 3.37 & 0.44 & $0.33,0.59$ & 0.56 & $0.41,0.77$ \\
\hline \multicolumn{7}{|c|}{$\begin{array}{l}\text { *Median }=17, \text { ranging from } 7 \text { to } 25 . \\
\dagger \text { Adjusted for maternal age and education, child's siblings, child's carer and child's BMI. } \\
\text { † Median of consumption: soft drinks } 0.5 \text { times per week; salty snacks } 0.2 \text { times per week; cakes } 0.5 \text { times per week; } \\
\text { sweets } 1.0 \text { time per week. } \\
\text { § Reference class. }\end{array}$} \\
\hline
\end{tabular}

foods with a high glycaemic index and a low fibre content ${ }^{(38)}$. These dietary factors may also increase energy intake, hence promoting a positive energy balance and increasing obesity risk. Decreasing energy density of foods along with other strategies may lead to sustained decreases in energy intake ${ }^{(39)}$.

The consumption of energy-dense foods might have a diluting effect on nutrient intake and total diet quality if they displace nutrient-dense foods such as milk and fruit ${ }^{(40,41)}$. In the present study, increased consumption of soft drinks, salty snacks (including fast foods) and sweets at an early stage was found to be associated with lower consumption of fruit and vegetables later in life. Fruit and vegetables have a low glycaemic index ${ }^{(42)}$ and a high fibre content, which per se may protect against excessive weight gain ${ }^{(43)}$. Consistent scientific evidence from epidemiological studies, such as case-control and prospective studies, support an inverse relationship between dietary consumption of fruit and vegetables and $\mathrm{CVD}^{(44-46)}$. Moreover, the WHO has highlighted the potential for the consumption of fruit and vegetables to reduce the risk of type 2 diabetes mellitus and to help to achieve or maintain a healthy body weight ${ }^{(47)}$. Previous studies $^{(13,31,40)}$, mostly conducted among school-aged children and adolescents, have found an inverse association between the consumption of energy-dense foods, mainly soft drinks, and the consumption of dairy foods. This relationship could be partially explained by the replacement of milk and milk products by soft drinks. However, in the present study, the consumption of energy-dense foods at 2 years of age was found to be not significantly associated with the consumption of dairy foods at 4 years of age. The reason for this may be that dairy foods are mainly consumed at breakfast (data not shown) and the prevalence of skipping breakfast is low among these children (4\%). On the other hand, this replacement of dairy foods by soft drinks may be more likely later in life and not at such young ages ${ }^{(34)}$.

The main finding of the present study was the association of high consumption of energy-dense foods at young ages with lower scores in healthy eating index 2 years later, particularly through lower consumption of fruit and vegetables. Decreased diet quality scores were found to be consistently associated with higher rates of all-cause mortality and rates and mortality of select diseases (e.g. CVD and cancer) in adulthood ${ }^{(27)}$. A pattern of high consumption of energy-dense food could also contribute, per se, to worst future health outcomes, namely obesity, as has been suggested in previous studies $^{(21,22)}$. Claims that energy-dense nutrient-poor foods can be part of a healthful diet ${ }^{(48)}$ should be discouraged.

Moreover, special attention should be given to the role of a carer in the establishment of a child's dietary patterns. At the age range focused upon in the present study, children do not shop for foods themselves; therefore; their eating patterns are reflective of the food shopping and nutrition knowledge of the carers. Thus, there is a great need for intervention from the carers, as they have the main responsibility for the eating habits of children.

A major strength of the present study is the use of a prospective approach to evaluate the association between poor food habits early in life and dietary habits a few years 
later. It used a sample of children from a population-based cohort, with characteristics similar to those of the remaining cohort. Only a few not relevant differences were found, such as maternal age and education, and these were controlled for in the adjusted analysis.

The accurate assessment of dietary intake in children is a challenge in epidemiological studies, and the use of parents as proxy reporters of their children's food consumption patterns is consensual. Dietary information reported by parents or carers at both ages could be biased, since they might not be always aware of all the foods eaten by the children when they are being taken care of by others. However, at this early stage of life, this is less likely to occur. A social desirability bias regarding food intake could be present, as dietary intake data were collected through face-to-face interviews. Data on consumption recorded could reflect attitudes about what should be consumed as opposed to what was really consumed. If lower intakes of 'unhealthy' foods and/ or higher intakes of 'healthy' foods have been reported, our associations could be underestimated.

The weak correlation found between $2 \mathrm{~d}$ food record and FFQ at 2 years of age could be the result of a low intake of these types of foods at this age, and a $2 \mathrm{~d}$ food record might not be a good method to validate extremely low intakes. Compared with food records, the FFQ seems to have overestimated the consumption at both ages, and as we did not expect to have a differential error, this would not compromise the conclusions of the present study regarding the associations found.

The application of a healthy eating index to summarise the overall diet quality represents a complementary approach to the study of single foods and accounts for cumulative and interactive effects of nutrients and foods and thus may provide a more comprehensive approach.

In conclusion, the consumption of energy-dense foods at young ages is associated with the diet quality of children, particularly in relation to the adequate consumption of fruit and vegetables.

As dietary habits of childhood might persist into adulthood, the present results suggest that the consumption of energydense nutrient-poor foods should be limited in childhood in order to prevent lifelong adverse effects on the diet quality of children.

\section{Acknowledgements}

The authors thank all the members of the research team and the staff of Generation XXI for their essential and generous assistance.

Generation XXI has been funded by the Operational Health Program - XXI Health, Community support framework III (co-funded by Feder), Administração Regional de Saúde do Norte, Fundação Calouste Gulbenkian and Fundação para a Ciência e Tecnologia (FCT - PTDC/SAU-ESA/108577/2008). These funders had no role in the design and analysis of the study or in the writing of this article.

The authors' contributions are as follows: S. V. was responsible for the analysis and interpretation of the data and wrote the first draft of the paper; A. O. and C. L. were also responsible for the analysis and interpretation of the data. All authors contributed to the concept and design of the study and paper review

None of the authors has any conflicts of interest to declare.

\section{References}

1. Kant AK (2003) Reported consumption of low-nutrientdensity foods by American children and adolescents: nutritional and health correlates, NHANES III, 1988 to 1994. Arch Pediatr Adolesc Med 157, 789-796.

2. Gibson S (2008) Sugar-sweetened soft drinks and obesity: a systematic review of the evidence from observational studies and interventions. Nutr Res Rev 21, 134-147.

3. Malik VS, Popkin BM, Bray GA, et al. (2010) Sugarsweetened beverages and risk of metabolic syndrome and type 2 diabetes: a meta-analysis. Diabetes Care 33, 2477-2483.

4. Forshee RA, Anderson PA \& Storey ML (2008) Sugarsweetened beverages and body mass index in children and adolescents: a meta-analysis. Am J Clin Nutr 87, $1662-1671$.

5. O'Neil CE, Fulgoni VL III \& Nicklas TA (2011) Association of candy consumption with body weight measures, other health risk factors for cardiovascular disease, and diet quality in US children and adolescents: NHANES 1999-2004. Food Nutr Res 55, 5794-5806.

6. Robyn RL, Robert JM \& John DR (2008) Pucker up: the effects of sour candy on your patients' oral health. A review of the dental erosion literature and $\mathrm{pH}$ values for popular candies. Northwest Dent 87, 20-1, 24-5, 28-9 passim.

7. Moore SC, Carter LM \& van Goozen S (2009) Confectionery consumption in childhood and adult violence. $\mathrm{Br} J$ Psychiatry 195, 366-367.

8. Khawaja O, Gaziano JM \& Djousse L (2011) Chocolate and coronary heart disease: a systematic review. Curr Atheroscler Rep 13, 447-452.

9. Buitrago-Lopez A, Sanderson J, Johnson L, et al. (2011) Chocolate consumption and cardiometabolic disorders: systematic review and meta-analysis. BMJ 343, d4488.

10. Listl S (2011) Family composition and children's dental health behavior: evidence from Germany. J Public Health Dent 71, 91-101.

11. Roblin L (2007) Childhood obesity: food, nutrient, and eating-habit trends and influences. Appl Physiol Nutr Metab 32, 635-645.

12. Rosenheck R (2008) Fast food consumption and increased caloric intake: a systematic review of a trajectory towards weight gain and obesity risk. Obes Rev 9, 535-547.

13. Bowman SA, Gortmaker SL, Ebbeling CB, et al. (2004) Effects of fast-food consumption on energy intake and diet quality among children in a national household survey. Pediatrics 113, 112-118

14. Wang YC, Bleich SN \& Gortmaker SL (2008) Increasing caloric contribution from sugar-sweetened beverages and $100 \%$ fruit juices among US children and adolescents, 1988-2004. Pediatrics 121, e1604-e1614.

15. Piernas C \& Popkin BM (2010) Trends in snacking among U.S. children. Health Aff (Millwood) 29, 398-404.

16. World Health Organization (2004) Health Behaviour in School-aged Children (HBSC) Study. International Report from the 2001/2002 Survey. Geneva: World Health Organization. 
17. Gregory J, Lowe S, Bates CJ, et al. (2000) National Diet and Nutrition Survey: Young People Aged 4-18 Years. Vol. 1. Report of the Diet and Nutrition Survey. London: TSO.

18. World Health Organization (2008) Health Behaviour in School-aged Children (HBSC) Study. International Report from the 2005/2006 Survey. Geneva: World Health Organization.

19. Malik VS, Schulze MB \& Hu FB (2006) Intake of sugarsweetened beverages and weight gain: a systematic review. Am J Clin Nutr 84, 274-288.

20. Ambrosini GL, Emmett PM, Northstone K, et al. (2012) Identification of a dietary pattern prospectively associated with increased adiposity during childhood and adolescence. Int J Obes (Lond) 36, 1299-1305.

21. Johnson L, Mander AP, Jones LR, et al. (2008) Energy-dense, low-fiber, high-fat dietary pattern is associated with increased fatness in childhood. Am J Clin Nutr 87, 846-854.

22. Johnson L, Mander AP, Jones LR, et al. (2008) A prospective analysis of dietary energy density at age 5 and 7 years and fatness at 9 years among UK children. Int J Obes (Lond) 32, 586-593.

23. Farris RP, Nicklas TA, Myers L, et al. (1998) Nutrient intake and food group consumption of 10-year-olds by sugar intake level: the Bogalusa Heart Study. J Am Coll Nutr 17, 579-585.

24. Forshee RA \& Storey ML (2001) The role of added sugars in the diet quality of children and adolescents. J Am Coll Nutr 20, 32-43.

25. Libuda L, Alexy U, Buyken AE, et al. (2009) Consumption of sugar-sweetened beverages and its association with nutrient intakes and diet quality in German children and adolescents. Br J Nutr 101, 1549-1557.

26. Frary CD, Johnson RK \& Wang MQ (2004) Children and adolescents' choices of foods and beverages high in added sugars are associated with intakes of key nutrients and food groups. J Adolesc Health 34, 56-63.

27. Wirt A \& Collins CE (2009) Diet quality - what is it and does it matter? Public Health Nutr 12, 2473-2492.

28. Collison KS, Zaidi MZ, Subhani SN, et al. (2010) Sugarsweetened carbonated beverage consumption correlates with BMI, waist circumference, and poor dietary choices in school children. BMC Public Health 10, 234.

29. French SA, Story M, Neumark-Sztainer D, et al. (2001) Fast food restaurant use among adolescents: associations with nutrient intake, food choices and behavioral and psychosocial variables. Int J Obes Relat Metab Disord 25, 1823-1833.

30. Coulthard H, Harris G \& Emmett P (2010) Long-term consequences of early fruit and vegetable feeding practices in the United Kingdom. Public Health Nutr 13, 2044-2051.

31. Marshall TA, Eichenberger Gilmore JM, Broffitt B, et al. (2005) Diet quality in young children is influenced by beverage consumption. J Am Coll Nutr 24, 65-75.

32. Alves E, Lunet N, Correia S, et al. (2011) Medical record review to recover missing data in a Portuguese birth cohort: agreement with self-reported data collected by questionnaire and inter-rater variability. Gac Sanit 25, 211-219.

33. Birthcohorts.net (2011) Generation XXI. http://birthcohorts. net $/$ bch $2 /$ ?action $=$ show \&UserID $=18$ (retrieved 20 October 2012).

34. Akbar A, Anal AK \& Ansari FA (2013) Prevalence and antibiogram study of and in poultry meat. Asian PacJ Trop Biomed 3, 163-168.

35. World Health Organization (2006) Food and Nutrition Policy for Schools: A Tool for the Development of School Nutrition Programmes in the European Region. Copenhagen: World Health Organization, The Regional Office for Europe.

36. WHO Multicentre Growth Reference Study Group (2006) WHO Child Growth Standards: Length/Height-for-age, Weight-for-age, Weight-for-length, Weight-for-height and Body Mass Index-for-age: Methods and Development. Geneva: World Health Organization.

37. Ludwig DS, Peterson KE \& Gortmaker SL (2001) Relation between consumption of sugar-sweetened drinks and childhood obesity: a prospective, observational analysis. Lancet 357, 505-508.

38. Ebbeling CB, Pawlak DB \& Ludwig DS (2002) Childhood obesity: public-health crisis, common sense cure. Lancet 360, 473-482.

39. Rolls BJ, Roe LS \& Meengs JS (2006) Reductions in portion size and energy density of foods are additive and lead to sustained decreases in energy intake. Am J Clin Nutr 83, 11-17.

40. Vartanian LR, Schwartz MB \& Brownell KD (2007) Effects of soft drink consumption on nutrition and health: a systematic review and meta-analysis. Am J Public Health 97, 667-675.

41. Paeratakul S, Ferdinand DP, Champagne CM, et al. (2003) Fast-food consumption among US adults and children: dietary and nutrient intake profile. J Am Diet Assoc 103, $1332-1338$.

42. Foster-Powell K, Holt SH \& Brand-Miller JC (2002) International table of glycemic index and glycemic load values: 2002. Am J Clin Nutr 76, 5-56.

43. Ludwig DS, Pereira MA, Kroenke CH, et al. (1999) Dietary fiber, weight gain, and cardiovascular disease risk factors in young adults. JAMA 282, 1539-1546.

44. Bazzano LA, Serdula MK \& Liu S (2003) Dietary intake of fruits and vegetables and risk of cardiovascular disease. Curr Atheroscler Rep 5, 492-499.

45. He FJ, Nowson CA \& MacGregor GA (2006) Fruit and vegetable consumption and stroke: meta-analysis of cohort studies. Lancet 367, 320-326.

46. Dauchet L, Amouyel P, Hercberg S, et al. (2006) Fruit and vegetable consumption and risk of coronary heart disease: a meta-analysis of cohort studies. J Nutr 136, 2588-2593.

47. Key TJ (2011) Fruit and vegetables and cancer risk. $\mathrm{Br} J$ Cancer 104, 6-11.

48. Nitzke S \& Freeland-Graves J (2007) Position of the American Dietetic Association: total diet approach to communicating food and nutrition information. J Am Diet Assoc 107, $1224-1232$. 